\title{
Long-term outcomes of microwave endometrial ablation for treatment of patients with menorrhagia: A retrospective cohort study
}

\author{
KOHEI NAKAMURA*, KENTARO NAKAYAMA, KAORI SANUKI*, TOSHIKO MINAMOTO, \\ TOMOKA ISHIBASHI, EMI SATO, HITOMI YAMASHITA, MASAKO ISHIKAWA and SATORU KYO
}

Department of Obstetrics and Gynecology, Shimane University School of Medicine, Izumo, Shimane 6938501, Japan

Received July 15, 2017; Accepted September 27, 2017

DOI: $10.3892 / 01.2017 .7208$

\begin{abstract}
This study aimed to describe the long-term outcomes of patients with menorrhagia treated with microwave endometrial ablation (frequency, $2.45 \mathrm{GHz}$ ), as well as to identify factors associated with recurrence or re-surgery. This retrospective cohort study was conducted from 2007 to 2015 at Shimane University Hospital in Japan. Patients with severe menorrhagia and a desire to preserve their uterus were included in the study. Clinical factors associated with recurrence of menorrhagia or re-surgery were analyzed with a multivariable logistic regression model. Of 160 microwave endometrial ablation candidates, 100 had uterine myomas, 20 adenomyosis, 26 functional excessive menstruation, and 12 endometrial polyps. In the full cohort, age $(<40)$ and uterine cavity length $(\geq 10)$ were associated with recurrence of menorrhagia and re-surgery. Among patients with myomas, age $(<48)$ and number of myomas $(\geq 4)$ were associated with recurrence, and largest myoma size $(\geq 5)$ and preoperative hemoglobin level $(<9 \mathrm{mg} / \mathrm{dl})$ were associated with re-surgery. Among subjects with adenomyosis, uterine cavity length $(\geq 10)$ was associated with recurrence. Microwave endometrial ablation is thought to be a highly efficacious method to control menorrhagia caused by functional bleeding and endometrial polyps. However, microwave endometrial ablation may be less effective for patients younger than 48 years with myomas, especially those with 4 or more myomas, or with a myoma $5 \mathrm{~cm}$ or larger in size, and for patients with adenomyosis who have a thickened myometrium. These clinical factors may be
\end{abstract}

Correspondence to: Dr Kentaro Nakayama, Department of Obstetrics and Gynecology, Shimane University School of Medicine, 89-1 Enyacho, Izumo, Shimane 6938501, Japan

E-mail:kn88@med.shimane-u.ac.jp

*Contributed equally

Key words: menorrhagia, microwave endometrial ablation, recurrence, re-surgery, uterine myoma useful predictors of success in selecting candidates for microwave endometrial ablation.

\section{Introduction}

Severe genital bleeding is one of the most common problems affecting women; it can affect a woman's physical, social, and emotional quality of life. There are a variety of causes of abnormal uterine bleeding, such as myomas, dysfunctional bleeding, endometrial polyps, endometrial malignant diseases, uterine arteriovenous malformations (AVMs), retained products of conception, and gestational trophoblastic disease.

Kanaoka at Iseikai Hospital (Osaka, Japan) first developed microwave endometrial ablation (MEA; frequency, $2.45 \mathrm{GHz}$ ) for functional menorrhagia (1). The uterine cavity is irradiated with microwaves at $2.45 \mathrm{GHz}$ to ablate the endometrium with a thin curved applicator, including the basal layer, thus decreasing the menstrual amount. The MEA technique was introduced to the Shimane University Hospital in August 2007. MEA was approved as an advanced medical treatment by the Ministry of Health, Labour and Welfare of Japan and our facility started to provide MEA treatment in June 2009. In April 2012, MEA was approved for national health insurance coverage as code K863-3: hysteroscope-assisted endometrial ablation.

Approximately 40,000 women in Japan are known to undergo hysterectomies annually. Twenty-five percent of these women may be able to avoid hysterectomy by undergoing MEA treatment (2). After endometrial ablation was introduced in the UK, the number of hysterectomies decreased by one third (3). Our previous report showed that MEA is effective in controlling menorrhagia and life-threatening uterine hemorrhage (4).

One hundred and sixty-nine patients at our hospital underwent MEA treatment in the past 8 years. We have previously evaluated the efficacy and safety of MEA, compared with conventional hysterectomy $(2,5)$, and found that it is effective, safe, and cost-effective in patients with excessive menstruation $(2,5)$. MEA is considered a standard treatment for patients with excessive menstruation resistant to conservative therapy. However, the long-term outcomes of this treatment modality are still unknown. 
The primary aim of this study was to describe the long-term outcomes of MEA in our institution. The secondary aim was to identify the predictors of menorrhagia recurrence or re-surgery after MEA.

\section{Materials and methods}

Patient selection and monitoring. This was a retrospective cohort study conducted from August 2007 to August 2015 at Shimane University Hospital in Shimane, Japan. Women who underwent MEA were identified and enrolled in the study. All patients gave written informed consent for the procedure and for study participation after proper explanation of the risks and benefits of the procedure. The inclusion criteria were severe menorrhagia, premenopausal status, no desire for childbearing, and a desire to preserve the uterus, as well as availability for at least 6 months of follow-up after MEA. Patients diagnosed with endometrial carcinoma after surgery were excluded from the study, as were those who did not undergo magnetic resonance imaging (MRI) evaluation before surgery. Data regarding patient characteristics, preoperative clinical findings, and procedure complications were extracted from the medical records. Before MEA was covered by health insurance in Japan, MEA was approved by the Ethics Committee of Shimane University's Medical Department; the same committee approved this study.

Patients were asked to schedule an initial postoperative follow-up visit 1 month after MEA, followed by an additional visit 6 months after the procedure. At these visits, a visual analog scale (VAS) with a maximum score of 10 was used to grade menstrual blood loss, menstrual cramping (dysmenorrhea), and patient satisfaction. The recurrence of menorrhagia after MEA was defined as the need for new pharmacotherapeutic interventions or occurrence of new symptoms such as extraordinary urinary frequency, accompanied by uterine enlargement. The time to recurrence was defined as the time in months from the procedure until the new treatment or symptoms began. Re-surgery was defined as worsening menorrhagia with a concomitant symptom-related total hysterectomy. We have previously reported the short-term efficacy of MEA in 76 of 169 patients who were included in this study (2).

Ablation procedure and follow-up. To perform the MEA, the lower abdominal region, vulva, femoral region, and vaginal cavity were sterilized with iodine, and ablation was performed using a Microtaze (Alfresa Pharma, Osaka, Japan) according to procedure guidelines, with the microwave output at $70 \mathrm{~W}$ for $50 \mathrm{sec}$. Transabdominal or rectal ultrasonography was used for intra-procedure monitoring (6). The follow-up period ranged from 10 to 96 months, with a median of 35.5 months.

Statistical analyses. Univariate analysis was performed using binomial logistic regression for ordered categorical variables. Patient clinicopathological characteristics included in the model were age at diagnosis, uterine cavity length ( $<10$ vs. $\geq 10 \mathrm{~cm}$ ), diagnosis (myoma/adenomyosis vs. others), myoma type (submucosal vs. intramural), largest myoma size $(<5 \mathrm{vs} . \geq 5 \mathrm{~cm})$, number of myomas on preoperative MRI ( $<4$ vs. $\geq 4)$, and preoperative hemoglobin concentration ( $<9 \mathrm{vs} . \geq 9 \mathrm{mg} / \mathrm{dl}$ ). The endpoints of the analysis were
Table I. Patient baseline characteristics $(\mathrm{n}=160)$.

\begin{tabular}{lc}
\hline Characteristic & $\begin{array}{c}\text { Median (range), } \\
\text { number (\%) }\end{array}$ \\
\hline Age (years) & $47(34-56)$ \\
Uterine cavity length (cm) & $9(7-14.5)$ \\
Diagnosis & \\
Myomas & $100(63 \%)$ \\
Adenomyosis & $20(13 \%)$ \\
Functional excessive menstruation & $26(16 \%)$ \\
Endometrial polyps & $12(7.5 \%)$ \\
Simple endometrial hyperplasia & $2(1.3 \%)$ \\
\hline
\end{tabular}

recurrence of menorrhagia and re-surgery. These data were plotted as Kaplan-Meier curves, and statistical significance was determined using the log-rank test. Variables that were initially entered into the model included those indicated to be significant $(\mathrm{P}<0.30)$ in the univariate analysis. These variables were hypothesized to potentially affect recurrence or re-surgery and were entered into the multivariate analysis.

Multivariate prognostic analysis was performed using a Cox proportional hazards model, and data from patients lost to follow-up were censored. Statistical analyses were conducted using the Statistical Package for the Social Sciences for Windows software, Version 19.0 (IBM Corp., Armonk, NY, USA). All reported P-values were two-sided, and $\mathrm{P}<0.05$ was considered to indicate a statistically significant difference.

\section{Results}

Patient characteristics. Of 169 patients enrolled in this study, 5 were excluded from analysis due to a final diagnosis of endometrial carcinoma, and 4 were excluded due to the lack of MRI evaluation before the MEA procedure. Data from 160 patients were analyzed in this report. Patient characteristics are presented in Table I. Patients ranged in age from 34 to 56 years, with a median age of 47 years. All patients had a chief complaint of excessive menstruation. Uterine myomas were present in 100 patients (63\%), adenomyosis in 20 patients (13\%), functional excessive menstruation in 26 patients (16\%), endometrial polyps in 12 patients (7.5\%), and simple endometrial hyperplasia in 2 patients $(1.3 \%)$. In women with a combination of uterine myomas and adenomyosis, we judged which was dominant in each patient using MRI evaluation and classified the patient in the appropriate group. The preoperative hemoglobin concentration ranged from 2.7 to $14.3 \mathrm{mg} / \mathrm{dl}$; the mean was $9.6 \mathrm{mg} / \mathrm{dl}$. The uterine cavity length, as determined on performing MRI, ranged from 7 to $14.5 \mathrm{~cm}$, with a mean of $9 \mathrm{~cm}$.

Univariate and multivariate analyses of prognostic factors in the full cohort. In the entire cohort, the rate of menorrhagia recurrence was $18.1 \%(29 / 160)$ and the rate of re-surgery was $9.3 \%(15 / 160)$.

A univariate analysis was performed using age $(<40$ or $\geq 40$ years), diagnosis (uterine myoma, adenomyosis, functional bleeding, endometrial polyps, or others), and uterine 

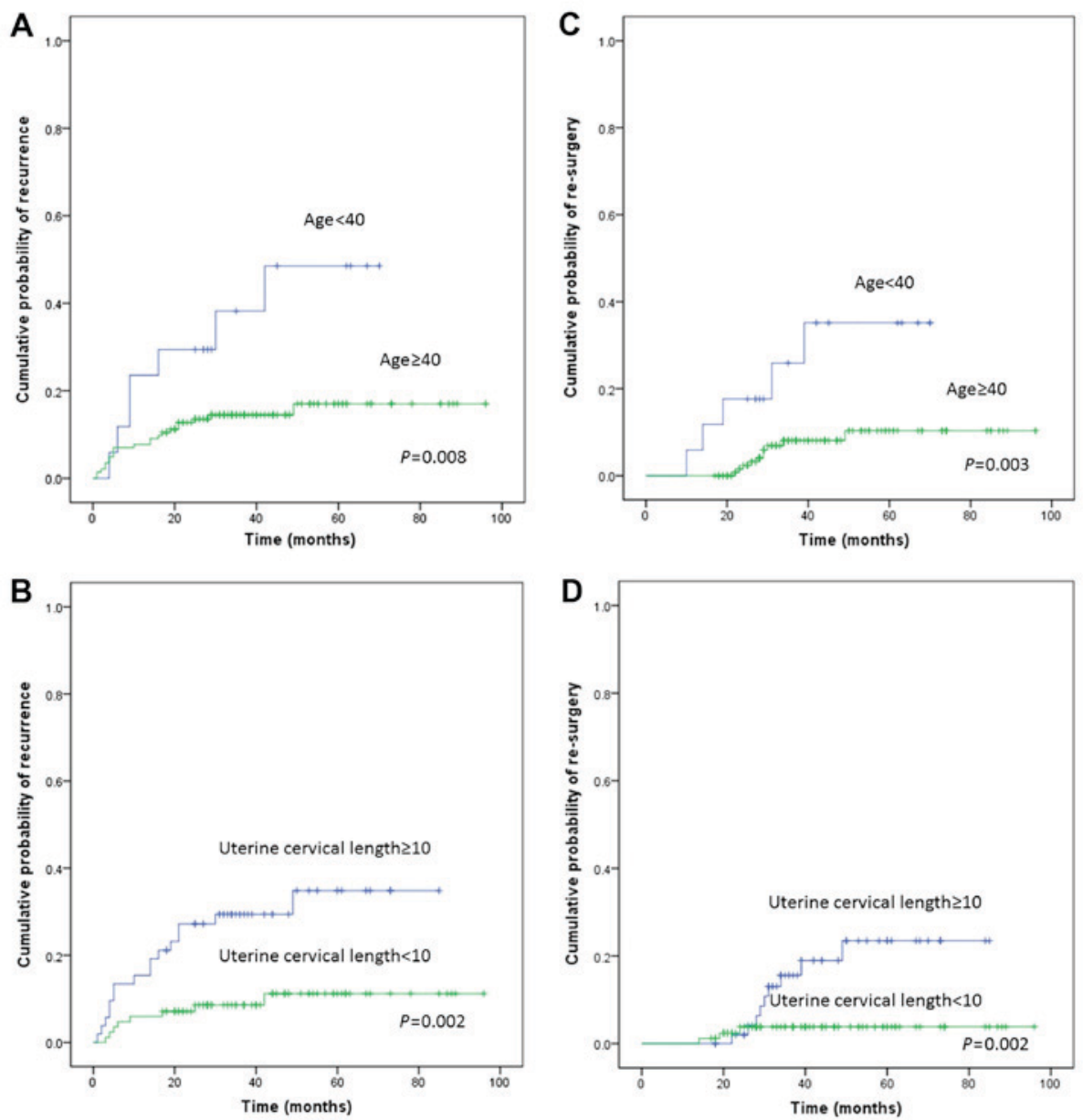

Figure 1. (A) Cumulative probability of recurrence of menorrhagia in the full cohort of women aged $\geq 40$ years. (B) The cumulative probability of recurrence of menorrhagia in the full cohort of women whose uterine cervical length is $\geq 10 \mathrm{or}<10 \mathrm{~cm}$. (C) The cumulative probability of re-surgery in the full cohort of women aged $\geq 40$ years. (D) The cumulative probability of re-surgery in the full cohort of women whose uterine cervical length is $\geq 10 \mathrm{or}<10 \mathrm{~cm}$.

cavity length ( $\geq 10$ or $<10 \mathrm{~cm}$ ) as possible variables. Diagnosis was categorized into 2 groups: i) myoma/adenomyosis; and ii) others, including functional bleeding and endometrial polyps. This analysis identified age $(\mathrm{P}=0.008$; Fig. 1A), uterine cavity length $(\mathrm{P}=0.002$; Fig. $1 \mathrm{~B})$, and diagnosis $(\mathrm{P}=0.007)$ as potential predictors of recurrence. A multivariate analysis confirmed that age $<40$ [hazard ratio (HR), 3.992; 95\% confidence interval $(\mathrm{CI})$ : $1.560-10.217 ; \mathrm{P}=0.004]$ and uterine cavity length $\geq 10$ ( $\mathrm{HR}, 4.035 ; 95 \% \mathrm{CI}: 1.706-9.541 ; \mathrm{P}=0.001)$ were independent risk factors for recurrence (Table II). Univariate and multivariate analyses were also performed on re-surgery. As shown in Table III, the univariate analysis revealed that age ( $\mathrm{P}=0.003$; Fig. 1C), uterine cavity length ( $\mathrm{P}=0.015$; Fig. 1D), and diagnosis of myoma/adenomyosis $(\mathrm{P}=0.132)$ were potential predictors of re-surgery. The multivariate analysis showed that age (HR, 5.618, 95\% CI: 1.678-18.806; $\mathrm{P}=0.005)$ and uterine cavity length (HR, 5.041; 95\% CI: 1.353-18.779; $\mathrm{P}=0.016)$ were independent risk factors for re-surgery (Table III).

Univariate and multivariate analyses of prognostic factors in patients with uterine myomas. We next performed a subgroup analysis of patients with uterine myomas. In patients with uterine myomas, the rate of menorrhagia recurrence was $19.0 \%(19 / 100)$ and the rate of re-surgery was $13.0 \%(13 / 100)$.
We first set various cut-off values and performed statistical analyses. We finally decided to use optimal cut-off values and set the age to 48 years, cut-off value of largest myoma size to $5 \mathrm{~cm}$, and cut-off value of number of myomas to four, which gave the significant differences statistically.

A univariate analysis was performed using age $(<48$ or $\geq 48$ ), myoma type (submucosal or intramural), largest myoma size ( $\geq 5$ or $<5 \mathrm{~cm}$ ), number of myomas on preoperative MRI $(\geq 4$ or $<4)$, uterine cavity length $(\geq 10$ or $<10)$, and preoperative hemoglobin concentration $(<9$ or $\geq 9 \mathrm{mg} / \mathrm{dl})$. This analysis identified age $(\mathrm{P}=0.022$; Fig. $2 \mathrm{~A})$, largest myoma size $(\mathrm{P}=0.073)$, number of myomas $(\mathrm{P}=0.021$; Fig. $2 \mathrm{~B})$, and uterine cavity length $(\mathrm{P}=0.061)$ as potential predictors of recurrence. A multivariate analysis confirmed that age $<48$ years (HR, 3.465; 95\% CI: 1.147-10.468; $\mathrm{P}=0.028$ ) and number of myomas $\geq 4$ (HR, 2.993; 95\% CI: 1.200-7.466; $\mathrm{P}=0.019$ ) were independent risk factors for recurrence (Table IV). Univariate and multivariate analyses were also performed on re-surgery. As shown in Table $\mathrm{V}$, the univariate analysis revealed that age $(\mathrm{P}=0.012)$, largest myoma size $(\mathrm{P}=0.006)$, number of myomas $(\mathrm{P}=0.013)$, uterine cavity length $(\mathrm{P}=0.023)$, and preoperative hemoglobin concentration $(\mathrm{P}=0.037)$ were potential predictors of re-surgery. The multivariate analysis showed that largest myoma size $\geq 5 \mathrm{~cm}$ (HR, 5.567: 95\% CI: 1.175-26.381; $\mathrm{P}=0.031)$ and preoperative hemoglobin concentration $<9 \mathrm{mg} / \mathrm{dl}(\mathrm{HR}$, 
Table II. Univariate and multivariate analyses of prognostic factors for menorrhagia recurrence in the entire cohort (rate of menorrhagia recurrence: $18.1 \%, 29 / 160)$.

\begin{tabular}{|c|c|c|c|c|c|c|c|}
\hline \multirow[b]{2}{*}{ Factors } & \multirow[b]{2}{*}{ Patients } & \multicolumn{3}{|c|}{ Univariate analysis } & \multicolumn{3}{|c|}{ Multivariate analysis } \\
\hline & & Hazard ratio & $95 \% \mathrm{CI}$ & P-value & Hazard ratio & $95 \% \mathrm{CI}$ & P-value \\
\hline \multicolumn{8}{|l|}{ Age at surgery, years } \\
\hline$<40$ & 17 & 3.019 & $1.282-7.106$ & 0.008 & 3.992 & $1.560-10.217$ & 0.004 \\
\hline$\geq 40$ & 143 & Ref & & & Ref & & \\
\hline \multicolumn{8}{|l|}{ Uterine cavity length, cm } \\
\hline$\geq 10$ & 62 & 3.524 & $1.508-8.237$ & 0.002 & 4.035 & $1.706-9.541$ & 0.001 \\
\hline$<10$ & 98 & Ref & & & Ref & & \\
\hline \multicolumn{8}{|l|}{ Diagnosis } \\
\hline Myoma/adenomyosis & 120 & 9.464 & $1.286-69.670$ & 0.007 & & & \\
\hline Others & 40 & Ref & & & & & \\
\hline
\end{tabular}

Ref, reference value; CI, confidence interval.

Table III. Univariate and multivariate analyses of prognostic factors for re-surgery in the entire cohort of patients (rate of re-surgery: $9.3 \%, 15 / 160)$.

\begin{tabular}{|c|c|c|c|c|c|c|c|}
\hline \multirow[b]{2}{*}{ Factors } & \multirow[b]{2}{*}{ Patients } & \multicolumn{3}{|c|}{ Univariate analysis } & \multicolumn{3}{|c|}{ Multivariate analysis } \\
\hline & & Hazard ratio & $95 \% \mathrm{CI}$ & P-value & Hazard ratio & $95 \% \mathrm{CI}$ & P-value \\
\hline \multicolumn{8}{|l|}{ Age at surgery, years } \\
\hline$<40$ & 17 & 4.477 & $1.530-13.102$ & 0.003 & 5.618 & $1.678-18.806$ & 0.005 \\
\hline$\geq 40$ & 143 & Ref & & & Ref & & \\
\hline \multicolumn{8}{|l|}{ Uterine cavity length, $\mathrm{cm}$} \\
\hline$\geq 10$ & 62 & 4.401 & $1.191-16.267$ & 0.015 & 5.041 & $1.353-18.779$ & 0.016 \\
\hline$<10$ & 98 & Ref & & & Ref & & \\
\hline \multicolumn{8}{|l|}{ Diagnosis } \\
\hline Myoma/Adenomyosis & 120 & 4.189 & $0.550-31.895$ & 0.132 & & & \\
\hline Others & 40 & Ref & & & & & \\
\hline
\end{tabular}

Ref, reference value; CI, confidence interval.

3.743; 95\% CI: 1.145-12.232; $\mathrm{P}=0.029)$ were independent risk factors for re-surgery (Table $\mathrm{V}$ ).

Univariate and multivariate analyses of prognostic factors in patients with adenomyosis. Finally, we performed a subgroup analysis of patients with adenomyosis. In patients with adenomyosis, the rate of menorrhagia recurrence was $35.0 \%$ (7/20).

We first set various cut-off values and performed statistical analysis. We finally decided to use an optimal cut-off value of the thickness of myometrium to $60 \mathrm{~mm}$, which gave the significant differences statistically.

A univariate analysis was performed using age $(<48$ or $\geq 48$ years), thickness of myometrium ( $\geq 60$ or $<60 \mathrm{~mm}$ ), uterine cavity length ( $\geq 10$ or $<10 \mathrm{~cm}$ ), and preoperative hemoglobin concentration $(<9$ or $\geq 9 \mathrm{mg} / \mathrm{dl})$. This analysis identified thickness of myometrium $(\mathrm{P}=0.046$; Fig. $3 \mathrm{~A})$ and uterine cavity length $(\mathrm{P}=0.013$; Fig. $3 \mathrm{~B})$ as potential predictors of recurrence.
A multivariate analysis confirmed that uterine cavity length $\geq 10 \mathrm{~cm}(\mathrm{HR}=15.467$; 95\% $\mathrm{CI}=1.792-133.519 ; \mathrm{P}=0.013)$ was an independent risk factor for recurrence (Table VI). An analysis of the predictors of re-surgery could not be performed in this subgroup due to the small sample size of patients who underwent re-surgery.

\section{Discussion}

The use of MEA was approved as an advanced medical treatment by the Ministry of Health, Labour and Welfare of Japan in December 2008. The pharmaceutical company, Alfressa Pharma, reported that over 500 patients underwent MEA treatment in Japan as of April 2012. Reports on the experiences and outcomes from several facilities have been published $(2,5,7)$. MEA has generally been associated with a good safety profile (8-10). We have previously reported comparison of MEA to conventional surgical treatments, including total abdominal hysterectomy and 
Table IV. Univariate and multivariate analyses of prognostic factors for recurrence in patients with uterine myomas (rate of recurrence: $19.0 \%, 19 / 100)$.

\begin{tabular}{|c|c|c|c|c|c|c|c|}
\hline \multirow[b]{2}{*}{ Factors } & \multirow[b]{2}{*}{ Patients } & \multicolumn{3}{|c|}{ Univariate analysis } & \multicolumn{3}{|c|}{ Multivariate analysis } \\
\hline & & $\begin{array}{c}\text { Hazard } \\
\text { ratio }\end{array}$ & $95 \%$ CI & $\mathrm{P}$ & $\begin{array}{c}\text { Hazard } \\
\text { ratio }\end{array}$ & $95 \% \mathrm{CI}$ & $\mathrm{P}$ \\
\hline \multicolumn{8}{|c|}{ Age at surgery, years } \\
\hline$<48$ & 56 & 3.358 & $1.113-10.132$ & 0.022 & 3.465 & $1.147-10.468$ & 0.028 \\
\hline$\geq 48$ & 44 & Ref & & & Ref & & \\
\hline \multicolumn{8}{|l|}{ Myoma type } \\
\hline Submucosal & 40 & 1.706 & $0.693-4.201$ & 0.238 & & & \\
\hline Intramural & 60 & Ref & & & & & \\
\hline \multicolumn{8}{|c|}{ Largest myoma size, $\mathrm{cm}$} \\
\hline$\geq 5$ & 50 & 2.356 & $0.895-6.205$ & 0.073 & & & \\
\hline$<5$ & 50 & Ref & & & & & \\
\hline \multicolumn{8}{|c|}{ Number of myomas on preoperative MRI } \\
\hline$\geq 4$ & 35 & 2.781 & $1.117-2.781$ & 0.021 & 2.993 & $1.200-7.466$ & 0.019 \\
\hline$<4$ & 65 & Ref & & & Ref & & \\
\hline \multicolumn{8}{|c|}{ Uterine cavity length, $\mathrm{cm}$} \\
\hline$\geq 10$ & 42 & 2.371 & $0.933-6.026$ & 0.061 & & & \\
\hline$<10$ & 58 & Ref & & & & & \\
\hline \multicolumn{8}{|c|}{ Preoperative hemoglobin concentration, $\mathrm{mg} / \mathrm{dl}$} \\
\hline$<9$ & 29 & 2.371 & $0.632-1.608$ & 0.313 & & & \\
\hline$\geq 9$ & 71 & Ref & & & & & \\
\hline
\end{tabular}

Ref, reference value; CI, confidence interval; MRI, magnetic resonance imaging.
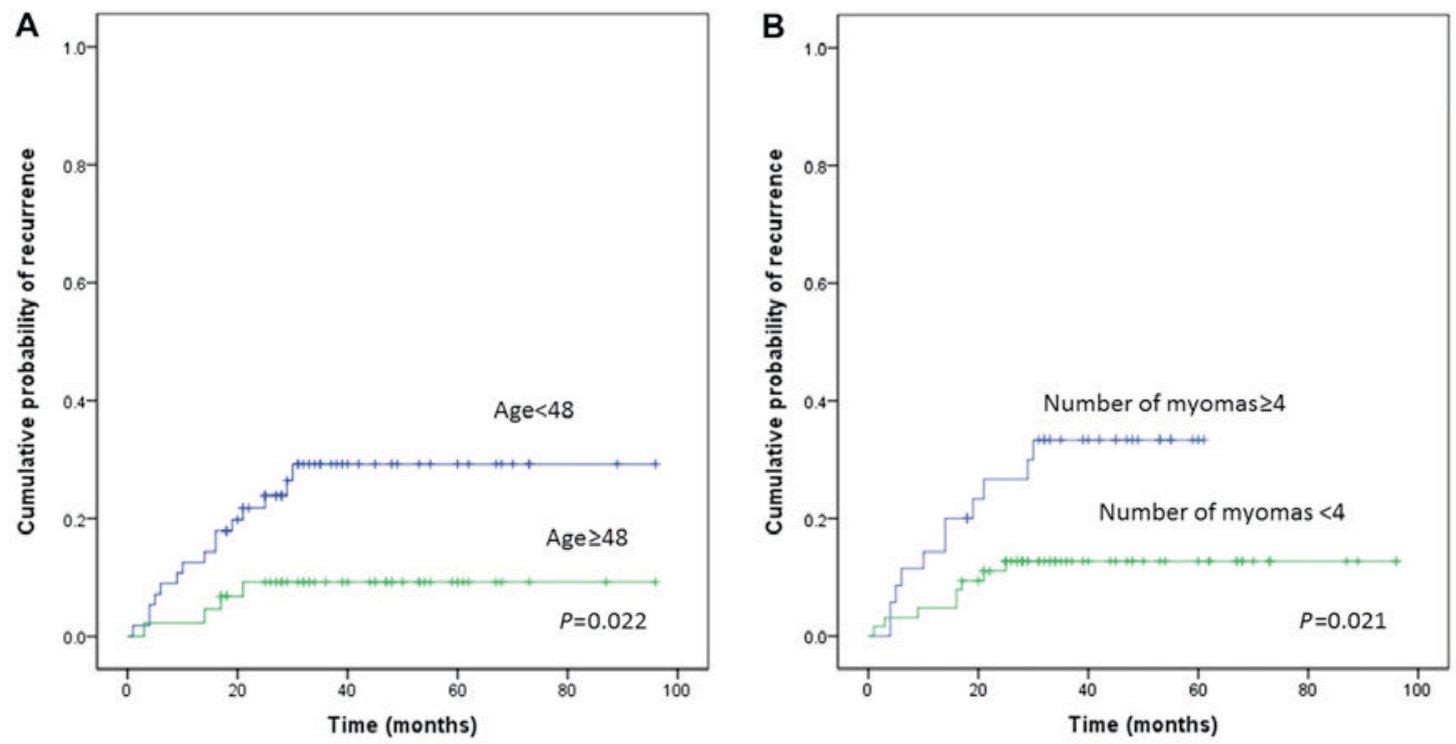

Figure 2. (A) The cumulative probability of recurrence of menorrhagia in women aged $\geq 48$ years with uterine myomas. (B) The cumulative probability of recurrence of menorrhagia in women with $\geq 4$ or $<4$ myomas.

laparoscopically assisted vaginal hysterectomy (5). MEA was associated with significantly less blood loss, as well as shorter surgery time and hospitalization period $(2,5)$. However, there are no reports addressing the long-term outcomes of MEA treatment.
To our knowledge, this is the first study to evaluate the long-term outcomes of patients after MEA (frequency, $2.45 \mathrm{GHz}$ ) and identify the prognostic factors for recurrence and re-surgery in patients with menorrhagia who underwent MEA. 
Table V. Univariate and multivariate analyses of prognostic factors for re-surgery in patients with uterine myomas (rate of re-surgery: $13.0 \%, 13 / 100)$.

\begin{tabular}{|c|c|c|c|c|c|c|c|}
\hline \multirow[b]{2}{*}{ Factors } & \multirow[b]{2}{*}{ Patients } & \multicolumn{3}{|c|}{ Univariate analysis } & \multicolumn{3}{|c|}{ Multivariate analysis } \\
\hline & & $\begin{array}{c}\text { Hazard } \\
\text { ratio }\end{array}$ & $95 \% \mathrm{CI}$ & P-value & $\begin{array}{l}\text { Hazard } \\
\text { ratio }\end{array}$ & $95 \% \mathrm{CI}$ & P-value \\
\hline \multicolumn{8}{|c|}{ Age at surgery, years } \\
\hline$<48$ & 56 & 5.522 & $1.222-24.955$ & 0.012 & 3.863 & $0.831-17.968$ & 0.085 \\
\hline$\geq 48$ & 44 & Ref & & & Ref & & \\
\hline \multicolumn{8}{|l|}{ Myoma type } \\
\hline Submucosal & 40 & 1.369 & $0.459-4.080$ & 0.571 & & & \\
\hline Intramural & 60 & Ref & & & & & \\
\hline \multicolumn{8}{|c|}{ Largest myoma size, $\mathrm{cm}$} \\
\hline$\geq 5$ & 50 & 6.294 & $1.392-28.451$ & 0.006 & 5.567 & $1.175-26.381$ & 0.031 \\
\hline$<5$ & 50 & Rref & & & Ref & & \\
\hline \multicolumn{8}{|c|}{ Number of myomas on preoperative MRI } \\
\hline$\geq 4$ & 35 & 3.993 & $1.228-12.986$ & 0.013 & 3.094 & $0.934-10.245$ & 0.065 \\
\hline$<4$ & 65 & Ref & & & Ref & & \\
\hline \multicolumn{8}{|c|}{ Uterine cavity length, $\mathrm{cm}$} \\
\hline$\geq 10$ & 42 & 4.010 & $1.102-14.589$ & 0.023 & & & \\
\hline$<10$ & 58 & Ref & & & & & \\
\hline \multicolumn{8}{|c|}{ Preoperative hemoglobin concentration, mg/dl } \\
\hline$<9$ & 29 & 3.038 & $1.015-9.091$ & 0.037 & 3.743 & $1.145-12.232$ & 0.029 \\
\hline$\geq 9$ & 71 & Ref & & & Ref & & \\
\hline
\end{tabular}

Ref, reference value; CI, confidence interval; MRI, magnetic resonance imaging.
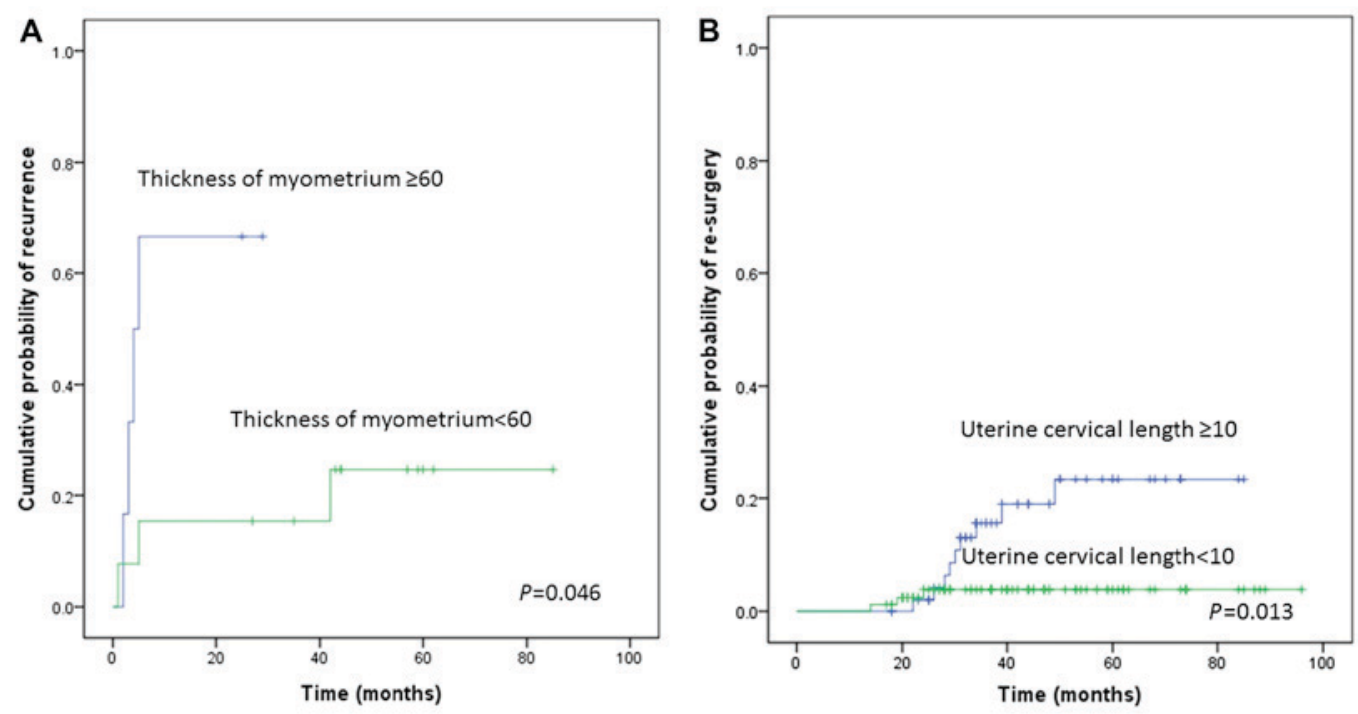

Figure 3. (A) The cumulative probability of recurrence of menorrhagia in women with adenomyosis whose myometrial thickness is $\geq 60 \mathrm{or}<60 \mathrm{~mm}$. (B) The cumulative probability of re-surgery in women with adenomyosis whose uterine cervical length is $\geq 10$ or $<10 \mathrm{~cm}$.

We have encountered several patients with myomas or adenomyosis that are resistant to MEA treatment. Myoma growth is thought to depend on ovarian hormones. As such, myomas are common among women before menopause and typically reduce or become asymptomatic after menopause (11-13), which occurs at a mean age of 51 years (14). Peddada et al (15) prospectively examined myoma growth rates using MRI. The median growth rate was $9 \%$ during 1 year. White women older than 45 years 
Table VI. Univariate and multivariate analyses of prognostic factors for recurrence in patients with uterine adenomyosis (rate of recurrence: $35.0 \%, 7 / 20)$.

\begin{tabular}{|c|c|c|c|c|c|c|c|}
\hline \multirow[b]{2}{*}{ Factors } & \multirow[b]{2}{*}{ Patients } & \multicolumn{3}{|c|}{ Univariate analysis } & \multicolumn{3}{|c|}{ Multivariate analysis } \\
\hline & & $\begin{array}{c}\text { Hazard } \\
\text { ratio }\end{array}$ & $95 \% \mathrm{CI}$ & P-value & $\begin{array}{l}\text { Hazard } \\
\text { ratio }\end{array}$ & $95 \% \mathrm{CI}$ & P-value \\
\hline \multicolumn{8}{|c|}{ Age at surgery, years } \\
\hline$<48$ & 13 & 1.940 & $0.431-8.734$ & 0.388 & & & \\
\hline$\geq 48$ & 7 & Ref & & & & & \\
\hline \multicolumn{8}{|c|}{ Thickness of myometrium, mm } \\
\hline$<60$ & 6 & 5.704 & $1.030-31.605$ & 0.046 & & & \\
\hline$\geq 60$ & 13 & Ref & & & & & \\
\hline \multicolumn{8}{|c|}{ Uterine cavity length, $\mathrm{cm}$} \\
\hline$\geq 10$ & 6 & 15.467 & $1.792-133.519$ & 0.013 & 15.467 & $1.792-133.519$ & 0.013 \\
\hline$<10$ & 12 & Ref & & & Ref & & \\
\hline \multicolumn{8}{|c|}{ Preoperative hemoglobin concentration, mg/dl } \\
\hline$<9$ & 12 & 0.868 & $0.193-3.891$ & 0.868 & & & \\
\hline$\geq 9$ & 8 & Ref & & & & & \\
\hline
\end{tabular}

Ref, reference value; CI, confidence interval.

had the slowest growth among the age groups, with a $2 \%$ growth rate. The relative odds of rapid growth $(>20 \%$ increase in volume per 6 months) in white women less than 35 years was 17 times higher than that of white women older than 45 years (15). Several studies in Japan showed similar growth rates of myomas in Japanese women (16-20). Therefore, we postulated that women younger than 48 years of age at MEA treatment might be at higher risk for recurrence or re-surgery. As expected, we found significantly higher rates of recurrence of menorrhagia and re-surgery in women younger than 48 years, compared with those 48 years and older. These findings suggest that the MEA treatment method may be less effective for younger women with myomas-namely, for women with a longer period of time until the onset of menopause. Furthermore, we found high rates of recurrence or re-surgery in women with myomas that are 4 or more in number or $5 \mathrm{~cm}$ or greater in maximum size, in those with a large uterus (uterine cavity length $\geq 10 \mathrm{~cm}$ ), and in those with a low preoperative hemoglobin level $(<9 \mathrm{mg} / \mathrm{dl})$. These clinical factors are all considered to reflect aggressive characteristics of myomas, thus it is not surprising that they are associated with an increased risk for recurrence and re-surgery.

We have also encountered several patients with adenomyosis resistant to MEA treatment (2). In that study, we found that MEA tended to be less effective in this patient population, than in women with myomas (2). We also found that multiple rounds of MEA treatment may more successfully control menorrhagia from adenomyosis (21). We postulated that the thickened myometrium in women with adenomyosis caused the resistance to MEA treatment and was associated with recurrence or re-surgery. The results of the present study support this hypothesis, as there was a higher rate of recurrence of menorrhagia among women with adenomyosis in which the myometrium is $60 \mathrm{~mm}$ or thicker, compared with those in which it is thinner than $60 \mathrm{~mm}$. Furthermore, there was a high rate of recurrence in all women with an enlarged uterus (uterine cavity length $\geq 10 \mathrm{~cm}$ ). These findings suggest that the MEA treatment method may be less effective for adenomyosis associated with a thickened myometrium or an enlarged uterus.

MEA treatment showed extremely high efficacy for functional bleeding and endometrial polyps. The difference in efficacy for these conditions may be related to the depth of penetration of the microwaves. In the MEA procedure, only the endometrium can be ablated, therefore the myomas themselves or the adenomyosis itself cannot truly be ablated. However, although functional bleeding is not associated solely with the endometrium, ablation of the endometrium is nonetheless a good way to control menorrhagia. Similarly, when an endometrial polyp is small, it can be ablated easily using MEA.

The strength of our study is that it was conducted in a single facility in which a strict and well-defined MEA management policy was in place throughout the study period. However, there were some limitations in this study. First, our study is retrospective in design. Second, our data may have been affected by a small sample size effect because of errors made in assumptions while calculating the sample size, especially for adenomyosis. Similarly, we were not able to analyze the re-surgery rate in the adenomyosis group due to the small sample size. Finally, the discrepancy of prognostic factors between recurrence risk and re-surgery risk may be due to the differences between the number of re-surgery cases and the number of recurrence cases.

In conclusion, MEA is thought to be a highly efficacious method to control menorrhagia caused by functional bleeding and endometrial polyps. However, our results indicate that MEA may be less effective for patients younger than 48 years with myomas, especially for those with 4 or more myomas or those with a myoma $5 \mathrm{~cm}$ or larger in size. Our findings also 
suggest that MEA may be less effective for women with adenomyosis and an enlarged uterus. Assessment of these clinical parameters may be a method by which to predict resistance to MEA among patients with menorrhagia who are considering the procedure. Additional large-scale, prospective, multicenter studies are needed to confirm these results.

\section{References}

1. Kanaoka Y, Hirai K and Ishiko O: Microwave endometrial ablation for an enlarged uterus. Arch Gynecol Obstet 269: 30-32, 2003.

2. Nakayama K, Ishibashi K, Ishikawa M, Katagiri A, Katagiri H, Iida K, Nakayama N and Miyazaki K: Microwave endometrial ablation at a frequency of $2.45 \mathrm{GHz}$ for menorrhagia: Analysis of treatment results at a single facility. J Obstet Gynaecol Res 40: 224-229, 2014.

3. Overton C, Hargreaves J and Maresh M: A national survey of the complications of endometrial destruction for menstrual disorders: The MISTLETOE study. Minimally Invasive surgical techniques-laser, EndoThermal or Endoresection. Br J Obstet Gynaecol 104: 1351-1359, 1997.

4. Nakayama K, Rahman MT, Rahman M, Ishikawa M, Yeasmin S, Katagiri A, Iida K, Nakayama N, Aoki S and Miyazaki K: Microwave endometrial ablation is a highly efficacious way to emergently control life-threatening uterine hemorrhage. Arch Gynecol Obstet 283: 1065-1068, 2011.

5. Nakayama K, Yeasmin S, Katagiri A, Rahman MT, Rahman M, Ishikawa M, Iida K, Nakayama N, Aoki S and Miyazaki K: A comparative study between microwave endometrial ablation and conventional surgical procedures for treatment of menorrhagia. Clin Exp Obstet Gynecol 38: 33-37, 2011.

6. Kanaoka Y, Ishikawa N, Asakawa Y and Nakayama K: Practice guideline of MEA. http://www.alfresa-pharma.co.jp/microtaze/MEA. Accessed April 1, 2012.

7. Akashi Y, Shimizu A and Mizuuchi M: A survey of outcomes of microwave endometrial ablation for menorrhagia in our hospital. J Obstet Gynecol (Tokyo) 76: 229-233, 2009 (In Japanese).

8. Milligan MP and Etokowo GA: Microwave endometrial ablation for menorrhagia. J Obstet Gynaecol 19: 496-499, 1999.

9. Downes E and O'Donovan P: Microwave endometrial ablation in the management of menorrhagia: Current status. Curr Opin Obstet Gynecol 12: 293-296, 2000.
10. Cooper KG, Bain C, Lawrie L and Parkin DE: A randomized comparison of microwave endometrial ablation with transcervical resection of the endometrium; follow up at a minimum of five years. BJOG 112: 470-475, 2005.

11. Flake GP, Anderson J and Dixon D: Etiology and pathogenesis of uterine leiomyomas: A review. Environ Health Perspect 111: 1037-1054, 2003.

12. Sato F, Mori M, Nishi M, Kudo R and Miyake H: Familial aggregation of uterine myomas in Japanese women. J Epidemiol 12: 249-253, 2002 .

13. Faerstein E, Szklo M and Rosenshein N: Risk factors for uterine leiomyoma: A practice-based case-control study. I. African-American heritage, reproductive history, body size, and smoking. Am J Epidemiol 153: 1-10, 2001.

14. Shifren JL and Schiff I: Menopause. In: Berek \& Novak's gynecology. Berek JS, Rinehart RD and Hengst TC (eds). 14th edition. Lippincott Williams \& Wilkins, Philadelphia, PA, c2007.

15. Peddada SD, Laughlin SK, Miner K, Guyon JP, Haneke K, Vahdat HL, Semelka RC, Kowalik A, Armao D, Davis B and Baird DD: Growth of uterine leiomyomata among premenopausal black and white women. Proc Natl Acad Sci USA 105: 19887-19892, 2008.

16. Fedele L, Parazzini F, Luchini L, Mezzopane R, Tozzi L and Villa L: Recurrence of fibroids after myomectomy: A transvaginal ultrasonographic study. Hum Reprod 10: 1795-1796, 1995.

17. Hanafi M: Predictors of leiomyoma recurrence after myomectomy. Obstet Gynecol 105: 877-881, 2005.

18. Jacobson GF, Shaber RE, Armstrong MA and Hung YY: Changes in rates of hysterectomy and uterine conserving procedures for treatment of uterine leiomyoma. Am J Obstet Gynecol 196: 601. e1-6, 2007.

19. Nishiyama S, Saito M, Sato K, Kurishita M, Itasaka $T$ and Shioda K: High recurrence rate of uterine fibroids on transvaginal ultrasound after abdominal myomectomy in Japanese women. Gynecol Obstet Invest 61: 155-159, 2006.

20. Yoo EH, Lee PI, Huh CY, Kim DH, Lee BS, Lee JK and Kim D: Predictors of leiomyoma recurrence after laparoscopic myomectomy. J Minim Invasive Gynecol 14: 690-697, 2007.

21. Nakamura K, Nakayama K, Ishikawa M, Katagiri H, Katagiri A, Ishibashi T, Sato E, Asakawa Y and Kyo S: Efficacy of multiple microwave endometrial ablation technique for menorrhagia resulting from adenomyosis. J Obstet Gynaecol Res 41: $1769-1172,2015$. 